\title{
Comparative ultrastructure of trichomes on various organs of Rosa roxburghii
}

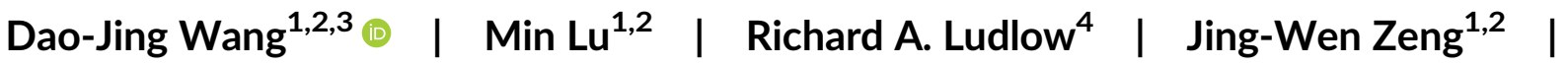 \\ Wen-Tao Ma ${ }^{1,2}$ | Hua-Ming $\mathrm{An}^{1,2}$
}

\author{
${ }^{1}$ Agricultural College, Guizhou University, \\ Guiyang, China \\ ${ }^{2}$ Guizhou Engineering Research Center for \\ fruit Crops, Guiyang, China \\ ${ }^{3}$ GuiYang Agricultural Test Center, Guiyang, \\ China \\ ${ }^{4}$ School of Biosciences, Cardiff University, Sir \\ Martin Evans Building, Museum Avenue, \\ Cardiff, UK

\section{Correspondence} \\ Hua-Ming An, Agricultural College, Guizhou \\ University, Guiyang 550025, China. \\ Email: anhuaming@hotmail.com

\section{Funding information} \\ The Talent Project of Guizhou Province, Grant/ \\ Award Number: 20164016; The National \\ Natural Science Foundation of China, Grant/ \\ Award Number: 31660549 \\ Review Editor: Mingying Yang
}

\begin{abstract}
Chestnut rose, $R$. roxburghii Tratt. (Rosaceae) (RR) is an important crop in China due to its nutritional and medicinal values. RR frequently produces trichomes on the surfaces of a diverse range of organs, however a genetic component exists to the control of trichome development, with some cultivars having significantly fewer trichomes to others. Certain varieties have fruits that are thickly covered with macroscopic trichomes, which is an undesirable trait for fruit processing and consumption. However, smooth-fruit cultivars exist, such as R. roxburghii Tratt. f. esetosa Ku (RRE). Despite their economic importance, the anatomical features of trichomes have not been explored in detail for these two chestnut rose germplasms. Here, we investigate the ultrastructure of trichomes distributed on the stem, sepal, and fruit of RR and RRE using transmission electron microscopy (TEM). The internal structure of stem prickle trichomes in RR and RRE was oval in shape and did not contain nucleoli or other organelles. The cell walls of stem prickles in RR are thick and the intercellular spaces occupied with liquid, whereas the cells wall of stem prickles in RRE are thin and have air-filled intercellular spaces. The cells of sepal acicular trichomes in RR and glandular trichomes (GTs) of sepals in RRE had similar vacuole sizes, cytoplasm content, intercellular spaces, and arrangement of plastids within cells. However, there were osmiophilic granules present in the GTs of RRE. The flagelliform trichomes in the sepals of the two germplasms are composed of oval or rod-shaped cells. Although the flagelliform trichomes in the sepals of the two germplasms had a similar internal structure, and both contained starch grains and plastids with visible thylakoid membranes, the flagelliform trichomes in the sepals of RR had a thinner cell wall and a higher proportion of cytoplasm which was more evenly distributed across the cell. There were granules that stained heavily with osmium tetroxide which occurred infrequently in the flagelliform trichomes of sepals in RRE but were not observed in RR. On the acicular trichomes of fruit in RR, the flagelliform trichomes and the GTs of fruit in RRE shared similar cell morphology, arrangement and vacuole size as well as intercellular space. Both the fruit flagelliform trichomes and GTs in RRE contain granules which stain heavily with osmium tetroxide, and the GTs contain plastids and
\end{abstract}


starch grains. These differences in trichome cell ultrastructure may be related to developmental processes or biological functions of the trichomes. These results also suggest that the two chestnut rose germplasms are good candidates for further study of trichome ontogeny in the genus and subsequent breeding of the smooth organ trait in this species.

\section{KEYWORDS}

$R$. roxburghii Tratt, $R$. roxburghii Tratt. f. esetosa Ku, trichomes, ultrastructure

\section{1 | INTRODUCTION}

Plant trichomes are specialized unicellular or multicellular structures that originate from the epidermal cell layer and are nearly ubiquitous in higher plants. The morphology of these epidermal protuberances varies greatly, depending on the organs or tissues they originate from, as well as the species of plant, and is a trait often used in plant classification (Wagner, 1991). Since the morphological and mechanical features (size, shape, density, orientation) of trichomes influence many aspects of plant physiology and ecology, their functions are diverse (Wagner, Wang, \& Shepherd, 2004). Besides their role in mechanical defense against biotic and abiotic stresses, trichomes also play role in the chemical defense of plants by producing a variety of metabolites (Wagner et al., 2004 Werker, 2000). Glandular trichomes (GTs), are present on approximately $30 \%$ of all known vascular plant species (Thomas, Rudall, Ellis, Savolainen, \& Glover, 2009; Appezzato-da-Glória et al., 2012; Muravnik, Kostina, \& Shavarda, 2016; Huchelmann, Boutry, \& Hachez, 2017; Uzelać, Janošević, Stojičić, \& Budimir, 2017; and others). Their principal function may be to produce pest or pollinator-interactive phytochemicals that are stored or volatilized at the plant surface, and are specific sites for the biosynthesis and excretion of secondary metabolites (Keene \& Wagner, 1985; Kelsey, Reynolds, \& Rodriguez, 1984; Venditti et al., 2014; Wagner et al., 2004) and antipathogenic proteins (Shepherd, Troy, Houtz, \& Wagner, 2005). Unicellular trichome development has been comprehensively studied in Arabidopsis thaliana, with a particular focus on trichome formation on leaves (Hülskamp, 2004; Ishida, Kurata, Okada, \& Wada, 2008; Pesch \& Hülskamp, 2009). Several regulators that function in distinct developmental pathways have been identified using classical molecular genetic approaches, for example, trichome initiation or formation, endo-reduplication, branch structure, and growth aspect (Chen et al., 2014; Schwab, Folkers, Ilgenfritz, \& Hülskamp, 2000; Szymanski, Lloyd, \& Marks, 2000). Recently, there has been much research interest in using cucumber (Cucumis sativus) as a model plant for studying multicellular trichomes (Chen et al., 2014; Cui et al., 2016; Li et al., 2015; Liu, Ezra, Cai, \& Ren, 2016; Pan, Bo, Cheng, \& Weng, 2015; Wang et al., 2016; Zhao et al., 2015).

R. roxburghii Tratt (RR) (Rosaceae) is a perennial rosebush native to China which is cultivated predominantly in Guizhou Province. Its cultivation area has been steadily expanding, with over 50,000 ha cropped annually, due to its high nutritional and medical value (Liu et al., 2012; van Rensburg et al., 2005). There are a range of drugs, health care products, cosmetics, and functional foods that utilize the plant (Lu, An, \& Li, 2016). RR presents trichomes that are widely distributed on leaves, stems, branches, pedicels, fruits and sepals (Wang, Zeng, Ma, Lu, \& An, 2019). The trichomes on the fruits are commonly called "prickles." These prickles negatively affect the appearance and perceived quality of the fruits and also hinder the production of processed products. $R$. roxburghii Tratt f. esetosa Ku (RRE) is a new germplasm without macroscopic prickles on the fruit, and it is generally considered to be a variant of $\mathrm{RR}(\mathrm{He}, \mathrm{Cao}, \mathrm{Li}, \& \mathrm{Pi}, 1994)$. RRE therefore offers significant advantages over RR for both the cultivation of fresh food and in the processing of derived products, as it is easier to harvest and process. Two distinct trichome morphotypes are identified on the organs of the two germplasms of Rosa roxburghii is investigated in this study. There are two major groups of trichome types in RR and RRE: non-glandular and glandular. Non-glandular trichome types include the ribbon, acicular, flagelliform, and triangular trichome types, and glandular trichomes include the capitate and elliptic glandular trichome types. There are flagelliform and acicular trichomes present in RR and four trichome types found in RRE, namely: triangular trichomes, capitate glandular trichomes, elliptic glandular trichomes, and flagelliform trichomes (Wang et al., 2019). Therefore, RRE and RR represent good candidates for the systematic study of trichome formation in this genus.

In rosaceous plants, detailed studies on the type and distribution of the vegetative organ trichomes has mainly been conducted in rubus and rose (Coyner, Skirvin, Norton, \& Otterbacher, 2005; Feng et al., 2015; Finn, Kempler, \& Moore, 2008; Kellogg, Branaman, Jones, Little, \& Swanson, 2011). However, detailed data of trichome types and distribution in vegetative parts of Rosa have not been shown in previous studies (Moore, 1991). Very little is known about the structure, ontogeny, and function of trichomes in $R$. roxburghii as well as their pertinence with other trichome types. Recently, types and diversity of trichomes were explored in R. roxburghii (Wang et al., 2019), but this study did not present clear and detailed anatomical structures of trichomes and especially lacked detail regarding the ultrastructure of trichomes. The lack of ultrastructure studies on RR and RRE trichomes has limited efforts to describe the molecular pathways involved in trichome development. Here, we provide data regarding the ultrastructure of trichome cells in RR and RRE. We describe the ultrastructure of trichomes on stems, fruit, and sepals of RR and RRE 
in order to lay the theoretical foundation for further research in the future.

\section{2 | MATERIALS AND METHODS}

\subsection{Plant materials}

Ten-year-old plants of RR "Guinong 5" and RRE were grown on yellow soil ( $\mathrm{pH}$ 6.3-6.5) in the fruit germplasm repository of Guizhou University, Guiyang, China (26 $\left.42.408^{\prime} \mathrm{N}, 106^{\circ} 67.353^{\prime} \mathrm{E}\right)$, with conventional water management and fertilizer application. The stems, fruits, and sepals were collected from the middle and upper canopy of 20 individual trees of both genotypes respectively in mid-late April 2017. The samples were quickly fixed in $3 \%$ glutaraldehyde solution for transmission electron microscopy.

\section{2 | Transmission electron microscopy (TEM)}

Samples were fixed in 3\% glutaraldehyde for $2 \mathrm{hr}$ and washed thoroughly with $0.1 \mathrm{~mol} \cdot \mathrm{L}^{-1}$ phosphate buffer $(\mathrm{pH}$ 6.8). Afterwards, they are post-fixed with $1 \%$ osmium tetroxide in phosphate buffer and subjected to following dehydration procedure in alcohol (50, 70, 80, 90,
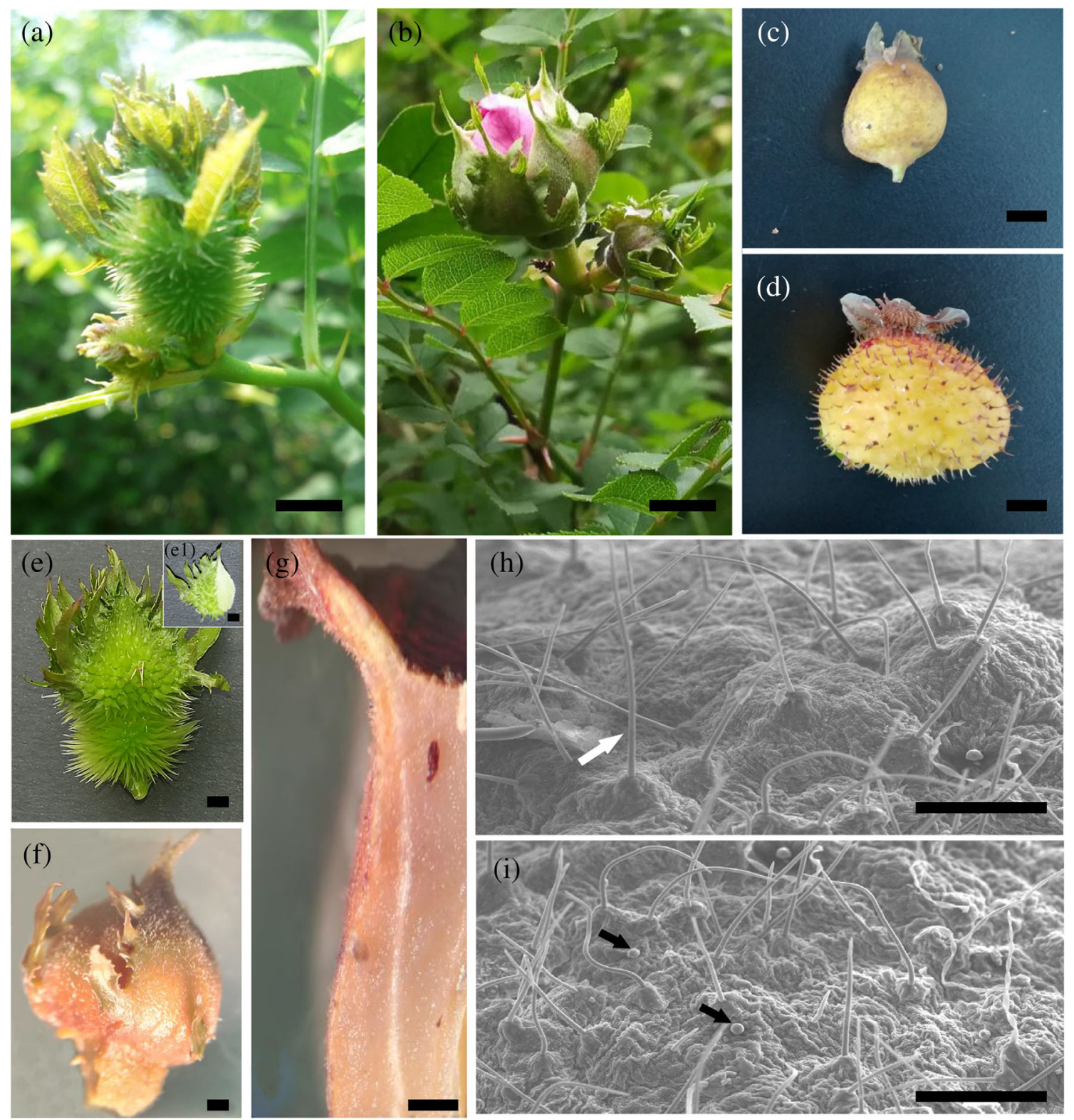

FIGURE 1 Appearance of trichomes in R. roxburghii Tratt (RR) and R. roxburghii Tratt. f. esetosa Ku (RRE). (a, d, e, e1) Macroscopic acicular trichomes and flagelliform trichomes of RR; (b, c, f, g) Macroscopic flagelliform trichomes of RRE; (h, i) SEM of trichomes in RRE, with the white arrow in figure $\mathrm{h}$ indicating the position of a flagelliform trichome and black arrows indicating glandular trichomes (GTs) in RRE of figure i; Scale bars: $1 \mathrm{~cm}(\mathrm{a}-\mathrm{d}) ; 1 \mathrm{~mm}(\mathrm{e}-\mathrm{g}) ; 200 \mu \mathrm{m}(\mathrm{h}-\mathrm{i})$ 
and $100 \%$, each of $10 \mathrm{~min}$ ) and two changes in $100 \%$ acetone (each of $15 \mathrm{~min}$ ), embedded in in Araldite resin CY 212, as described by Glauert and Glauert (1958). Ultrathin sections $(80 \mathrm{~nm})$ were transferred to formvar-coated grids and post-stained with uranyl acetate and lead citrate. Observations were made with JEM-1200EX scanning transmission electron microscope at $120 \mathrm{KV}$. JEM-1200EX TEM is used to examine the ultrastructure of trichomes. A total of 96 images of suitably high clarity were obtained and representative images selected for further analysis.

\section{3 | RESULTS}

\section{1 | Trichome types in RR and RRE}

Flagelliform and acicular trichomes are present in the fruits of RR (Figure 1a,d,e,e1). Whereas GTs and flagelliform trichomes were found in RRE (Figure 1b-c,f-i). The lack of acicular trichomes has a marked impact on the edibility of the fruit between RR (Figure 1d) and RRE (Figure 1c), whereby the fruit of RR is covered in large, lignified prickles and the fruit of RRE is smooth.

\section{2 | Internal structure of prickles of stem in RR and RRE}

TEM micrographs of stem prickles show that cells of RR are large, have a rounded shape, and are closely packed. The cell walls are thick and plasmodesmata are infrequent and the cells have a large vacuole, with few organelles observed in the cytoplasm (Figure 2a-c). There is a relatively small amount of cytoplasm, and plastids are found in the periphery of the cells in stem prickles of RR. This cytoplasmic area is electron dense and contains a diverse population of plastids, with a range of electron densities (Figure $2 b-e$ ). The intercellular space was filled with fluid (Figure 2d,e). In comparison, the cells of stem prickles in RRE are larger than those of RR, with a greater proportion of the cell occupied by the vacuole (Figure 2f). Similarly, the cytoplasm was limited to the periphery of the cell and contained plastids (Figure $2 \mathrm{~g}$ h). Cells are again closely packed, but cell walls are thinner and have even less frequent plasmodesmata than those of RR (Figure $2 \mathrm{i}-\mathrm{j}$ ). Contrastingly, the intercellular spaces of stem prickle cells in RRE were occupied by air, and no organelles were found (Figure $2 \mathrm{~g}-\mathrm{j}$ ).

\section{3 | Internal structure of trichomes in sepal of RR and RRE}

There are acicular trichomes and flagelliform trichomes on the sepals of RR. Under TEM observation, results show that the cells of acicular trichomes on sepals of RR have a variety of morphologies, are larger, arranged loosely with larger intercellular spaces, have thick cell walls with plasmodesmata that occur infrequently and a large vacuole (Figure 3a). The cells are without an obvious nucleus or organelles, have a low content of cytoplasm, and are highly degraded and senescent, with cellular debris visible within their vacuoles (Figure $3 b-e$ ). A
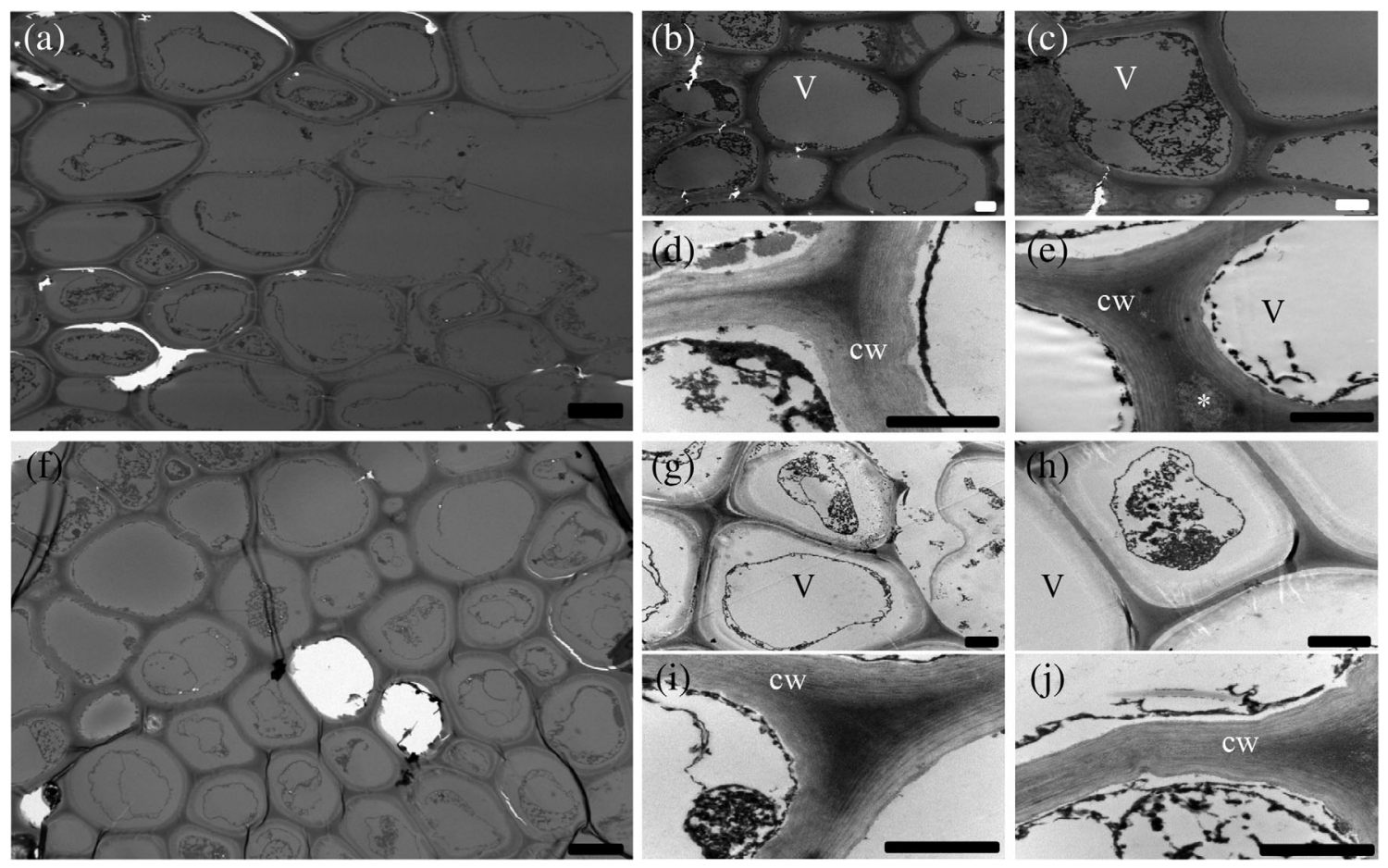

FIGURE 2 TEM images of stem prickles in R. roxburghii Tratt (RR) and R. roxburghii Tratt. f. esetosa Ku (RRE). (a) TEM of stem prickles of RR; b-e: Partial enlargement of figure a, unknown (asterisk); (f) TEM in stem prickles of RRE; (g-j) Partial enlarged version of figure f; cw: Cell wall; V: Vacuole; Scale bars: $10 \mu \mathrm{m}(\mathrm{a}, \mathrm{f}) ; 2 \mu \mathrm{m}(\mathrm{b}-\mathrm{e}, \mathrm{g}-\mathrm{j})$ 
diverse population of plastids are found throughout the cell (Figure 3d-e). In flagelliform trichomes of RR, the cells have oval and rod-shaped. The oval cells are larger, more loosely arranged, have thick cell walls with infrequent plasmodesmata and large intercellular spaces, with large vacuoles and low cytoplasmic content (Figure $3 f-h$ ). Additionally, a small number of starch grains were present, as were a range of plastids (Figure 3g-h). The rod-shaped cells are elongated and closely arranged with small intercellular spaces, have thin cell walls with infrequent plasmodesmata, and cells have small vacuoles with a high content of cytoplasm (Figure $3 f-j$ ). Some plastids were observed with dilated thylakoid membranes, as well as a range of different shaped plastids, with varying electron densities in the rodshaped cells of RR (Figure 3f,h).

Flagelliform and GTs are present on the sepals of RRE. Under TEM observation, the cells in flagelliform trichomes are either rodshaped or more oval, and irregular in shape (Figure 3k). Rod-shaped cells of flagelliform trichomes are large, closely packed with small intercellular spaces, have thick cell walls with infrequent plasmodesmata, with large vacuoles, and have starch grains and plastids with dilated thylakoids (Figure $3 n-0$ ). They have infrequent plasmodesmata, a low proportion of cytoplasm density, and plastids of different shapes and electron densities are present as well as granules which stain heavily with osmium tetroxide (Figure 3o). Conversely, the oval shaped cells are large and closely packed, with thick cell walls that have infrequent plasmodesmata and small intercellular spaces (Figure 3l-m). Cells have large vacuoles with a low proportion of cytoplasm, and also contain starch granules (Figure 3l-m). Plastids of different shapes and electron densities were present, as well as a small number of eosinophilic osmium stained granules (Figure $3 \mathrm{~m}$ ).

The cells of GTs are oval in shape with large vacuoles, tightly packed, have thin cell walls and frequent plasmodesmata with large intercellular spaces (Figure $3 p-t$ ). Plastids were abundant and had a
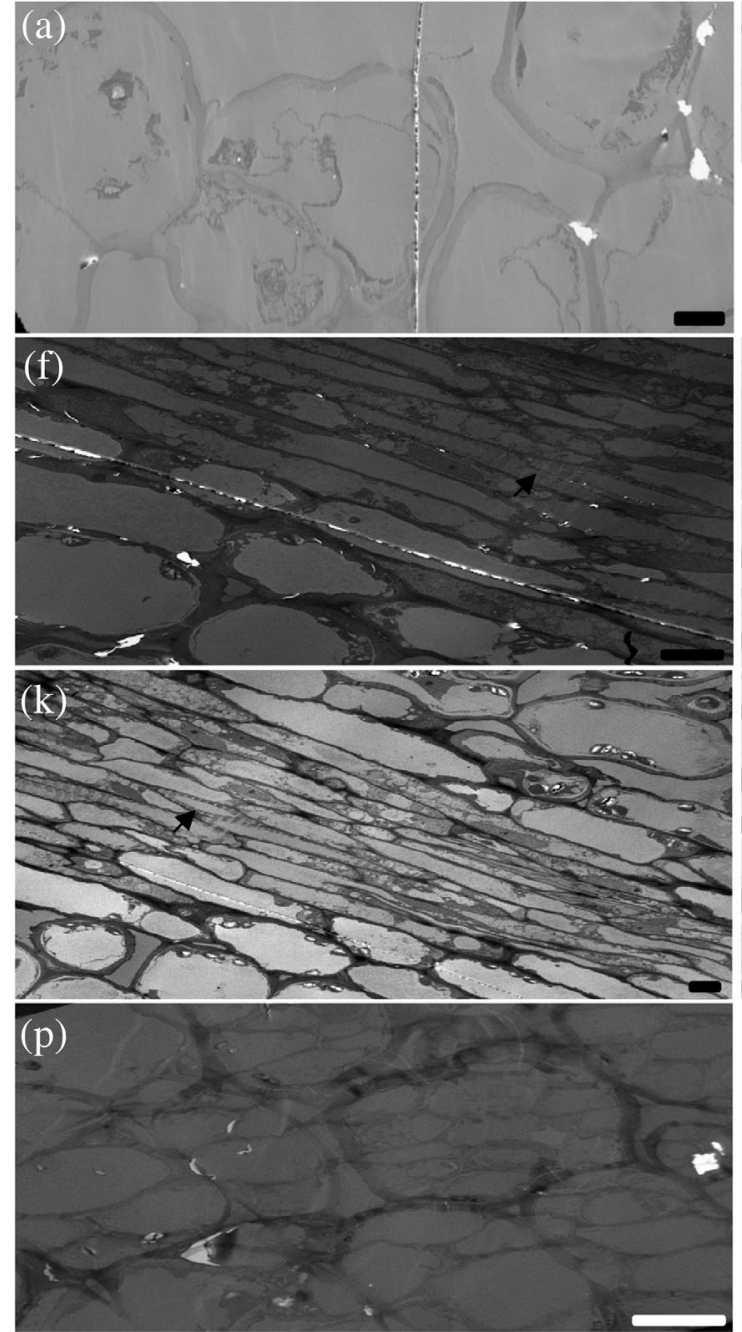
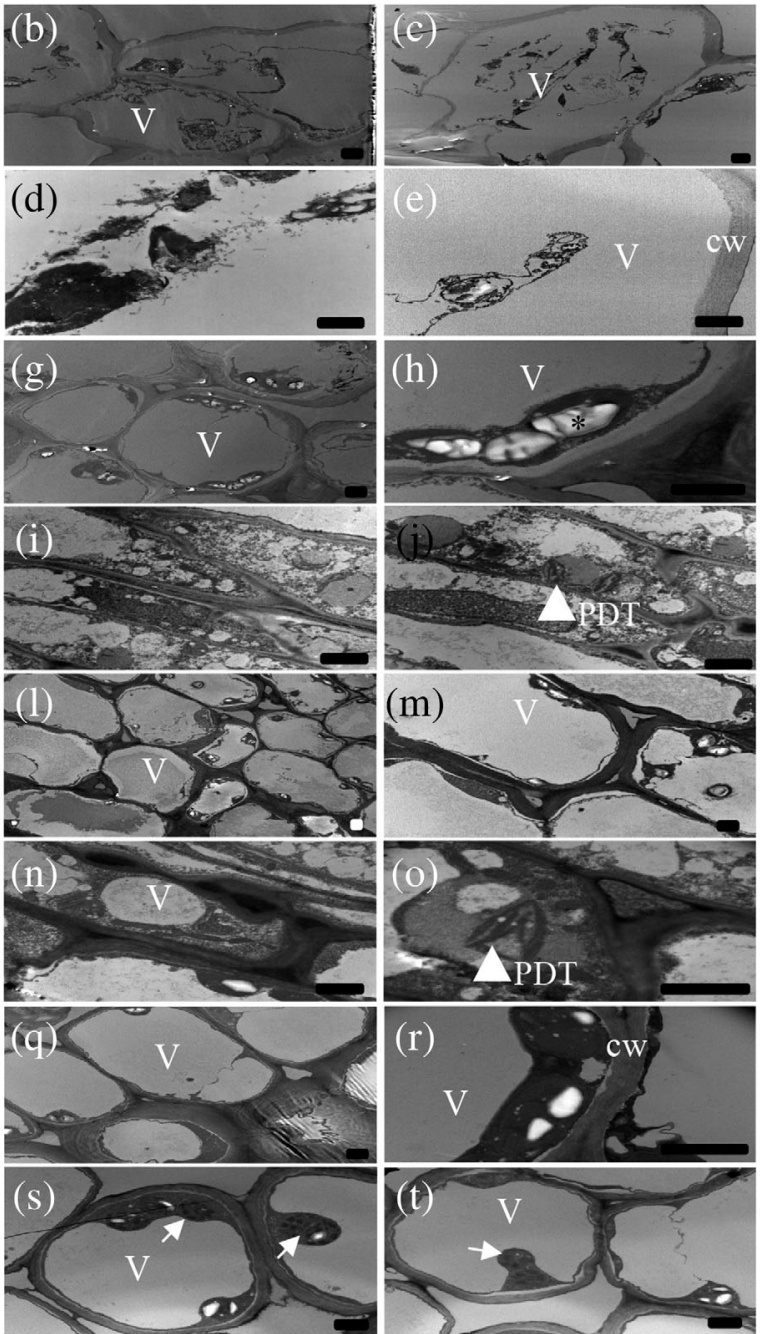

FIG URE 3 TEM images of trichomes in sepal of R. roxburghii Tratt (RR) and R. roxburghii Tratt. f. esetosa Ku (RRE). (a) TEM of acicular trichomes in sepals of RR; (b-e) Local magnification map of $a$; $f$ : TEM of flagellate trichomes in sepals of RR; (g-j) Local magnification map of $f$; (k) TEM map of flagellate trichomes in sepals of RRE; (l-o) Local magnification map of k; (p) TEM of GTs in sepals of RRE; (q-t) Local magnification map of p; cw: Cell wall; V: Vacuoles; PDT: Plastids with dilated thylakoids (triangle); starch grains (asterisk); plastids (white arrow); rod-shaped cells (black arrow) Scale bars: $10 \mu \mathrm{m}$ (a, f, k, p); $2 \mu \mathrm{m}$ (b-e, g-j, l-o, q-t) 
range of shapes and electron densities, as well as a small number of granules which stained heavily with osmium. Starch grains were also present (Figure $3 r-t$ ) and cells had a low cytoplasm content (Figure 3s-t).

\subsection{Internal structure of the fruit trichomes in RR and RRE}

Observations using TEM show that the fruits of RR are covered in acicular trichomes, where the cells are large and oval in shape, loosely arranged, and have thin cell walls, with large vacuoles and intercellular spaces (Figure $4 a-e)$. In addition, they contain abundant starch grains, a high cytoplasm content, and a range of plastids (Figure $4 d-e$ ). Contrastingly, there are flagelliform and glandular trichomes (GTs) on the fruit surface of RRE. The cells of flagelliform trichomes are oval, small, and loosely arrangement, have thin cell walls, with large vacuoles and intercellular spaces (Figure $4 \mathrm{f}-\mathrm{j}$ ), They have a low content of cytoplasm and do not frequently have plasmodesmata or have other organelles visible (Figure $4 \mathrm{~g}-\mathrm{j}$ ). Plastids are present, with a range of morphologies and electron densities, and there are starch grains and a small number of eosinophilic granules which stain heavily with osmium tetroxide (Figure $4 \mathrm{i}-\mathrm{j}$ ). Glandular trichome cells in RRE are oval, loosely arranged and small in size. They have a thin cell wall, infrequent plasmodesmata, a large vacuole surrounded by relatively little cytoplasm and large intercellular spaces (Figure 4k-o). Cells did not have nuclei visible, but starch grains, plastids and eosinophilic granules were present (Figure $4 \mathrm{I}-\mathrm{O}$ ).

\section{4 | DISCUSSION}

\subsection{Non-glandular trichomes (NGTs)}

The cell ultrastructure of stem prickles from plants of RR and RRE showed that the cell structure is broadly similar, but that key differences exist (Figure 2a-j). Both RR and RRE had a high degree of cell vacuolization (Figure 2c,h-i). However, we found an unknown substance in the cell wall of RR stem trichomes, which was not present in RRE. This unknown substance was not found in Rose (Gyoichi Asano, Kubo, \& Tanimoto, 2008) or rubus corchorifolius (Kellogg et al., 2011). It may be related to its material transportation channel of the matter in the intercellular space of stem prickles in RR, which also suggests that the transportation mode of stem prickles in RR may be different from that of RRE.
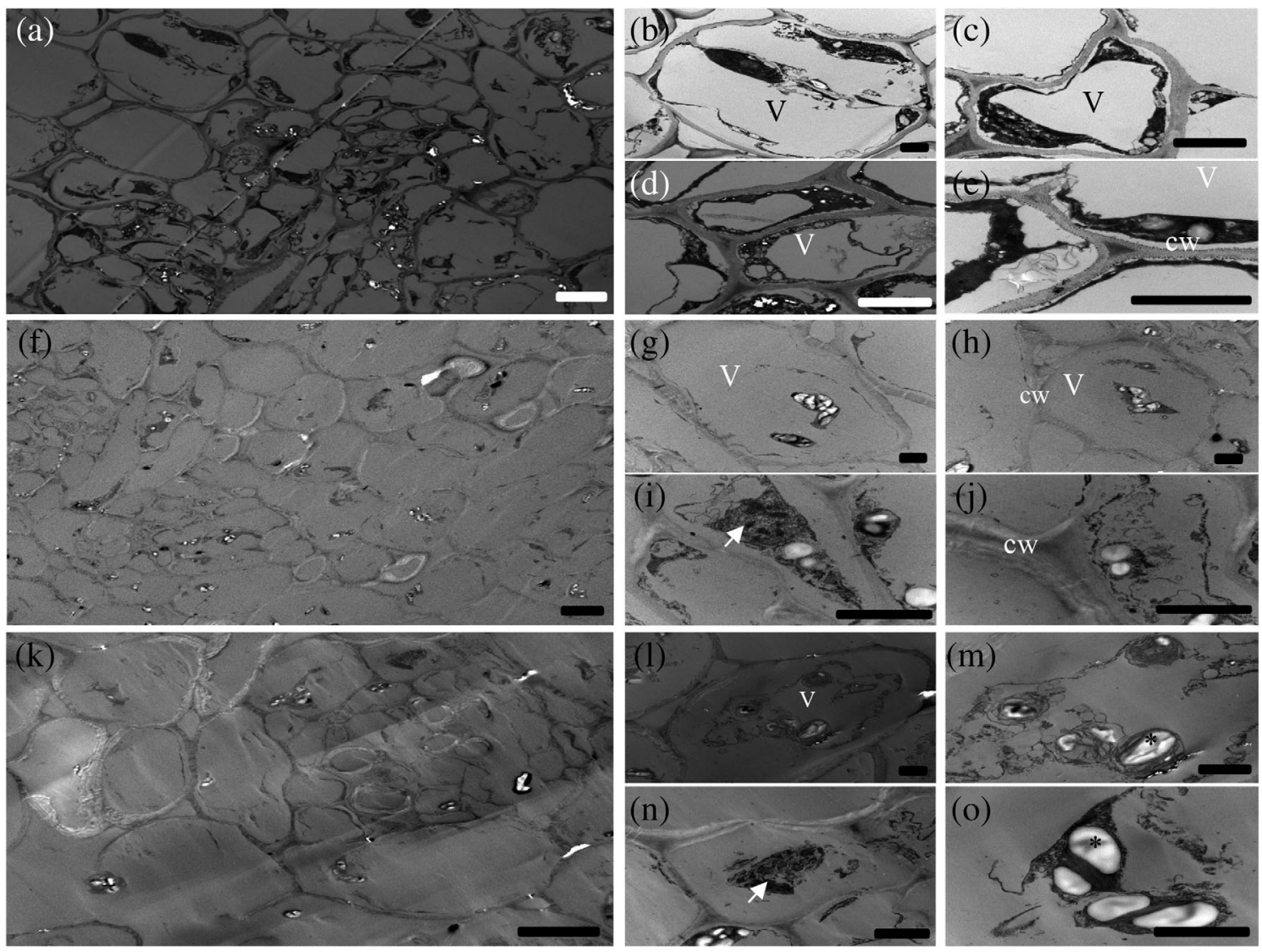

FIG URE 4 TEM images of trichomes in fruits of $R$. roxburghii Tratt (RR) and R. roxburghii Tratt. f. esetosa Ku (RRE). (a) TEM of acicular trichomes in fruit of RR; (b-e) local enlargement map of a; (f) TEM map of flagellate trichomes in fruit of RRE; (g-j) local enlargement map of $f$; (k) the GTs in fruit of RRE; (l-o) local enlargement map of k. Denotations: cell wall (cw); vacuoles (v); starch grains (asterisk); plastids (white arrows). Scale bars $=10 \mu \mathrm{m}(\mathrm{a}, \mathrm{f}, \mathrm{k}) ; 2 \mu \mathrm{m}$ (b-e, g-j, l-o) 
Key similarities exist in the internal structure of trichomes on fruits and sepals of RR and RRE. There is significant vacuolization in the cells of acicular and flagelliform trichomes on fruit and sepals of RR as well as in the cells of flagelliform trichomes in fruit and sepals of RRE (Figures $3 g-j, l-o$ and $4 b-e, g-j$ ). The high degree of vacuolization in the cells of acicular trichomes in RR, suggesting that the metabolic activity of the cells may be relatively low. As such, these trichomes may not be heavily involved in the developmental processes of the fruit or sepals of RR, and it is propose that the trichomes may just serve a protective purpose in RR and RRE from herbivores and phytophagous insects. On the other hand, a number of starch grains and plastids with dilated thylakoids in flagelliform trichomes of RR and RRE suggest that the metabolic activity may be higher and that they may be involved in the development process of RR and RRE.

In the flagelliform trichomes on the sepals of RR and RRE, a large number of organelles were present, suggesting that their metabolic activities are relatively high. It is possible that these trichomes may be involved in the synthesis of metabolites relating to sepal growth or development.

\section{2 | Glandular trichomes}

The cells of GTs in RRE display a high degree of vacuolization and have an abundance of organelles within the cytoplasm and plasmodesmata (Figures $3 q-t$ and $4 \mathrm{I}-0$ ), which may be related to its secretory or transport functions. These features are typical of secretory tissues with high metabolic activity, as found in mature GTs of Phillyrea latifolia (Gravano, Tani, Bennici, \& Gucci, 1998), Mentha piperita (Turner, Gershenzon, \& Croteau, 2000), Connarus suberosus (Denardi, Oliveira, \& Paiva, 2012), Helianthus annuus (Amrehn, Heller, \& Spring, 2014) and others. However, the cells of these trichomes were reported to contain large, well-defined nuclei, which were not visible in the GTs of RRE studied here, which may suggest an alternative function. We also frequently saw osmiophilic granules in GT cells of RRE; high osmiophilic granular content is found in the vacuoles of mature salt GT head cells in Ficus formosana (Chen \& Chen, 2007) and Teucrium polium leaf cells (Christodoulakis, Kogia, Mavroeidi, \& Fasseas, 2010), where they were shown to contain tannins. In addition, in tobacco seedlings exposed to toxic levels of cadmium, crystals containing high amounts of cadmium and calcium were formed in amorphous osmiophilic deposits in vacuoles of head cells of both short and tall trichomes (Choi et al., 2001).

\section{3 | RR and RRE}

There is a distinct internal structure to trichomes in RR and RRE. The cells of prickles on the stems of RR and RRE are oval, larger, closely packed, with a large vacuole and little cytoplasm, with plastids present (Figure 2a-j). A large volume of cytoplasm with numerous plastids indicates high metabolic activity of the cell in trichomes, for example, in Acanthopanax senticosus (Denardi et al., 2012) and sunflower (Amrehn et al., 2014). There are plastids visible in the stem prickles of
RR and RRE, which suggests low metabolic activity of these cells, this is also consistent with the rapid lignification that occurs in stem prickles. In RR, the intercellular space contains other substances than the stem prickles (Figure $2 \mathrm{~d}-\mathrm{e}$ ). The matter in the interstitial cells of RR stem may serve the purpose of increasing its mechanical strength, thus contributing to the resilient mechanical properties of these trichomes, however, further studies are needed to verify this.

Cells of acicular trichomes in sepals of RR and GTs in sepals of RRE were remarkably similar (Figure 3a-e). Compared with acicular trichomes in sepals of RR, the GTs cells in sepals of RRE are oval, closely packed, thin cell wall, and frequent plasmodesmata, in addition, there is a small amount of eosinophilic osmium particles in the cells of GTs (Figure 3p-t). Plasmodesmata are associated with the transport of material in cell, these results suggest that GTs cells in sepals of RRE might give a path of cell secretion of secondary metabolites or other material and water to transport quickly between the cells.

Cells of flagelliform trichomes in sepals of RR and RRE were oval or rod-shaped. The oval cells contained starch grains and had infrequent plasmodesmata (Figure 3g-h,l-m) and the rod-shaped cells contain plastids with dilated thylakoids (Figure $3 f, i-j, k, n-o$ ). There were starch grains and a few osmiophilic granules in the flagelliform trichomes (Figure 3i-j,n-o). With the naked eye, we observed that the sepals of RR and RRE covered by silver-white of trichomes (Figure 3ab), which may be related to the leucoplast in cells of trichomes.

In RRE, the flagelliform trichomes and GTs of fruit were similar to that of the cell morphology, arrangement, vacuole size and intercellular space of acicular trichomes of fruit in RR (Figure $4 \mathrm{f}-\mathrm{o}$ ). However, the main difference was that there were starch grains in the cells of flagellate trichomes (Figure 4g-j) and GTs in RRE (Figure 4I-o). Starch grains in trichomes can be involved in the coloration of cells and may be responsible for their silver-white appearance. The osmiophilic granules in the cells of fruit GTs in RRE are similar with the GTs of tobacco leaf and Ficus formosana, where they were shown to contain concentrated tannins (Chen \& Chen, 2007; Uzelać et al., 2017).

At present, the secretory pathways and the chemical components secreted from GTs in Rosa roxburghii are not well described. In tobacco, T-phylloplanins produced in short GT gland cells may be secreted to the gland extracellular spaces and then transferred outside of the glands through constrictions at the termini of intracellular spaces, which are presumed to be secretory pores of unknown structure (Uzelać et al., 2017). In T. farfara, the main constituents of CGT secretions are acidic polysaccharides, polyphenols (including flavonoids and tannins), and terpenoids. Pectins are usually necessary components of the GTs in the Asteraceae (Werker \& Fahn, 1981; Ascensäo \& Pais, 1987; Monteiro et al., 2001; Appezzato-Da-Glória, Hayashi, Cury, Soares, \& Rocha, 2008). Flavonoids are also shown in the glandular hairs of Sigesbeckia jorullensis (Heinrich, Pfeifhofer, Stabentheiner, \& Sawidis, 2002), Matricaria chamomilla (Andreucci, Ciccarelli, Desideri, \& Pagni, 2008) and Santolina ligustica (Pagni, Orlando, Masini, \& Ciccarelli, 2003). Formerly phenols were demonstrated in the glandular hairs of Sigesbeckia jorullensis (Heinrich et al., 2002) and Inula viscosa (Nikolakaki \& Christodoulakis, 2004), as 
well as in the idioblasts of Chresta sphaerocephala (Appezzato-DaGlória et al., 2008). Besides coltsfoot, terpenoids are found in the GTs of Artemisia campestris (Ascensäo \& Pais, 1987), Stevia rebaudiana (Tateo, Cornara, Bononi, Mariotti, \& Serrato-Valenti, 2001), Santolina ligustica (Pagni et al., 2003), Lychnophora reticulata (Alves, GobboNeto, \& Lopes, 2008), and Matricaria chamomilla (Andreucci et al., 2008).

In conclusion, our ultrastructural study provides an initial view of the inner structure of trichomes in Rosa roxburghii. Future studies should focus on the analysis of gene expression data generated by RNA-seq which may elucidate key transcription factors of multicellular trichome development in RR and RRE. The analysis of secondary metabolites in trichomes would be of great interest too, and may help elucidate semiochemical functions of the trichomes.

\section{ACKNOWLEDGMENTS}

This work was supported by grants from the National Natural Science Foundation of China (31660549) and the Talent Project of Guizhou Province (Project No. 20164016).

\section{CONFLICT OF INTEREST}

The authors declare no potential conflict of interest.

\section{AUTHOR CONTRIBUTIONS}

Dao-Jing Wang, Min Lu and Hua-Ming An conceived and designed the research. Dao-Jing Wang, Jing-Wen Zeng and Wen-Tao Ma performed the experiments. Dao-Jing Wang and Min Lu analyzed the data and wrote the paper. Richard A. Ludlow and Hua-Ming An revised the paper. All authors read and approved the manuscript.

\section{DATA AVAILABILITY STATEMENT}

All data generated or analysed during this study are included in this published article.

\section{ORCID}

Dao-Jing Wang (D) https://orcid.org/0000-0002-5654-0618

\section{REFERENCES}

Alves, K. C. M., Gobbo-Neto, L., \& Lopes, N. P. (2008). Sesquiterpene lac tones and flavonoids from Lychnophora reticulata Gardn. (Asteraceae). Biochemical Systematics and Ecology, 36, 434-436.

Amrehn, E., Heller, A., \& Spring, O. (2014). Capitate glandular trichomes of Helianthus annuus (Asteraceae): Ultrastructure and cytological development. Protoplasma, 251, 161-167.

Andreucci, A. C., Ciccarelli, D., Desideri, I., \& Pagni, A. M. (2008). Glandular hairs and secretory ducts of Matricaria chamomilla (Asteraceae): Morphology and histochemistry. Annales Botanici Fennici, 45, 11-18.

Appezzato-da-Glória, B., Da Costa, F. B., da Silva, V. C., Gobbo-Neto, L., Rehder, V. L. G., \& Hayashi, A. H. (2012). Glandular trichomes on aerial and underground organs in Chrysolaena species (Vernonieae Asteraceae): Structure, ultrastructure and chemical composition. Flora, 207, 878-887.

Appezzato-Da-Glória, B., Hayashi, A. H., Cury, G., Soares, M. K. M., \& Rocha, R. (2008). Occurrence of secretory structures in underground systems of seven Asteraceae species. Botanical Journal of the Linnean Society, 157, 789-796.
Ascensäo, L., Pais, \& M. S. S. (1987). Glandular trichomes of Artemisia campestris (ssp. maritima): ontogeny and histochemistry of the secretory product. Bot Gaz, 148, 221-227.

Chen, C., Liu, M., Jiang, L., Liu, X., Zhao, J., Yan, S., ... Zhang, X. (2014). Transcriptome profiling reveals roles of meristem regulators and polarity genes during fruit trichome development in cucumber (Cucumis sativus L.). Journal of Experimental Botany, 65, 4943.

Chen, C. C., \& Chen, Y. R. (2007). Study on laminar hydathodes of Ficus formosana (Moraceae) III. Salt injury of guttation on hydathodes. Botonical Studies, 48, 215-226.

Choi, Y.-E., Harada, E., Wada, M., Tsuboi, H., Morita, Y., Kusano, T., \& Sano, H. (2001). Detoxification of cadmium in tobacco plants: Formation and active secretion of crystals containing cadmium and calcium through trichomes. Planta, 213, 45-50.

Christodoulakis, N. S., Kogia, D., Mavroeidi, D., \& Fasseas, C. (2010). Anatomical and histochemical investigation of the leaf of Teucrium polium, a pharmaceutical sub-shrub of the Greek phryganic formations. Journal of Biological Research-Thessaloniki, 14, 199-209.

Coyner, M. A., Skirvin, R. M., Norton, M. A., \& Otterbacher, A. G. (2005). Thornlessness in blackberries: A review. Small Fruits Review, 4, 83-106.

Cui, J. Y., Miao, H., Ding, L. H., Wehner, T. C., Liu, P. N., Wang, Y., ... Gu, X. F. (2016). A new glabrous gene (csgl3) identified in trichome development in cucumber (Cucumis sativus I.). PLoS One, 11, e0148422.

Denardi, J. D., Oliveira, D. M. T., \& Paiva, E. A. S. (2012). Glandular trichomes in Connarus suberosus (Connaraceae): Distribution, structural organization and probable functions. Revista de Biología Tropical, 60, 505-513.

Feng, L. G., Luan, X. F., Wang, J., Xia, W., Wang, M., \& Sheng, L. X. (2015). Cloning and expression analysis of transcription factor rttg1 related to prickle development in rose (Rosa rugosa). Archives of Biological Sciences, 67, 98-98.

Finn, C. E., Kempler, C., \& Moore, P. P. (2008). Raspberry cultivars: what's new? what's succeeding? Where are breeding programs headed? Acta Horticulturae, 777, 777-777.

Glauert, A. M., \& Glauert, R. H. (1958). Araldite as an embedding medium for electron microscopy. The Journal of Biophysical and Biochemical Cytology, 4, 191-194.

Gravano, E., Tani, C., Bennici, A., \& Gucci, R. (1998). The ultrastructure of glandular trichomes of Phillyrea latifolia L. (Oleaceae) leaves. Annals of Botany, 81, 327-335.

Gyoichi Asano, H., Kubo, R., \& Tanimoto, S. (2008). Growth, structure and lignin localization in rose prickle. Bulletin of the Faculty of Agriculture, 93, 117-125.

He, Y. H., Cao, Y. L., Li, Z. L., \& Pi, L. D. (1994). The main economic traits and important vitamin content of 22 species of wild rose in China. Journal of Horticultural Science, 02, 158-164.

Heinrich, G., Pfeifhofer, H. W., Stabentheiner, E., \& Sawidis, T. (2002). Glandular hairs of Sigesbeckia jorullensis Kunth (Asteraceae): Morphology, histochemistry and composition of essential oil. Annals of Botany, 89, 459-469.

Huchelmann, A., Boutry, M., \& Hachez, C. (2017). Plant glandular trichomes: Natural cell factories of high biotechnological interest. Plant Physiology, 175(1), 2-66.

Hülskamp, M. (2004). Plant trichomes: A model for cell differentiation. Nature Reviews. Molecular Cell Biology, 5, 471-480.

Ishida, T., Kurata, T., Okada, K., \& Wada, T. (2008). A genetic regulatory network in the development of trichomes and root hairs. Annual Review of Plant Biology, 59, 365-386.

Keene, C. K., \& Wagner, G. J. (1985). Direct demonstration of duvatrienediol biosynthesis in glandular heads of tobacco trichomes. Plant Physiology, 79, 1026-1032. 
Kellogg, A. A., Branaman, T. J., Jones, N. M., Little, C. Z., \& Swanson, J. D. (2011). Morphological studies of developing Rubus prickles suggest that they are modified glandular trichomes. Botany, 89, 217-226.

Kelsey, R. G., Reynolds, G. W., \& Rodriguez, E. (1984). The chemistry of biologically active constituents secreted and stored in plant glandular trichomes. In E. Rodriguez, P. L. Healey, \& I. Mehta (Eds.), Biology and chemistry of plant trichomes (pp. 187-240). New York: Plenum Press.

Li, Q., Cao, C., Zhang, C., Zheng, S., Wang, Z., Wang, L., \& Ren, Z. (2015). The identification of Cucumis sativus glabrous 1 (csgl1) required for the formation of trichomes uncovers a novel function for the homeodomain-leucine zipper I gene. Journal of Experimental Botany, 66, 2515-2526.

Liu, X., Ezra, B., Cai, Y., \& Ren, H. (2016). Trichome-related mutants provide a new perspective on multicellular trichome initiation and development in cucumber (Cucumis sativusl). Frontiers in Plant Science, 7 , 1187-1187.

Liu, W., Li, S., Huang, X., Cui, J., Zhao, T., \& Zhang, H. (2012). Inhibition of tumor growth in vitro by a combination of extracts from Rosa roxburghii Tratt. and Fagopyrum cymosum. Asian Pacific Journal of Cancer Prevention, 13, 2409-2414.

Lu, M., An, H., \& Li, L. (2016). Genome survey sequencing for the characterization of the genetic background of Rosa roxburghii tratt and leaf ascorbate metabolism genes. PLoS One, 11(2), e0147530.

Monteiro, W. R., Castro, M. M., \& Mazzoni-Viveiros, S. C. (2001). Development and some histochemical aspects of foliar glandular trichomes of Stevia rebaudiana (Bert.) Bert. Asteraceae. Rev Bras Bot. 24, 349-357.

Moore, M. O. (1991). Classification and systematics of eastern North American Vitis L. (Vitaceae) north of Mexico. SIDA, 14, 339-367.

Muravnik, L. E., Kostina, O. V., \& Shavarda, A. L. (2016). Glandular trichomes of Tussilago farfara (Senecioneae, Asteraceae). Planta, 244(3), 737-752.

Nikolakaki, A., \& Christodoulakis, N. S. (2004). Leaf structure and cytochemical investigation of secretory tissues in Inula viscosa. Botanical Journal of the Linnean Society, 144, 437-448.

Pagni, A. M., Orlando, R., Masini, A., \& Ciccarelli, D. (2003). Secretory structures of Santolina ligustica Arrigoni (Asteraceae), an Italian endemic species. Israel Journal of Plant Sciences, 51, 185-192.

Pan, Y., Bo, K., Cheng, Z., \& Weng, Y. (2015). The loss-of-functionglabrous 3 mutation in cucumber is due to Itr-retrotransposon insertion in a class IV hd-zip transcription factor gene csgl3 that is epistatic overcsgl1. BMC Plant Biology, 15, 302.

Pesch, M., \& Hülskamp, M. (2009). One, two, three. Models for trichome patterning in arabidopsis ? Current Opinion in Plant Biology, 12, 587-592.

Schwab, B., Folkers, U., Ilgenfritz, H., \& Hülskamp, M. (2000). Trichome morphogenesis in arabidopsis. Philosophical Transactions of the Royal Society of London, 355, 879.

Shepherd, R. W., Troy, B. W., Houtz, R. L., \& Wagner, G. J. (2005). Phylloplanins of tobacco are defensive proteins deployed on aerial surfaces by short glandular trichomes. The Plant Cell, 17, 1851-1861.

Szymanski, D. B., Lloyd, A. M., \& Marks, M. D. (2000). Progress in the molecular genetic analysis of trichome initiation and morphogenesis in arabidopsis. Trends in Plant Science, 5, 214-219.
Tateo, F., Cornara, L., Bononi, M., Mariotti, M. G., \& Serrato-Valenti, G. (2001). Trichomes on vegetative and reproductive organs of Stevia rebaudiana (Asteraceae). Structure and secretory products. Plant Biosystems, 135, 25-37.

Thomas, M. M., Rudall, P. J., Ellis, A. G., Savolainen, V., \& Glover, B. J. (2009). Development of a complex floral trait: The pollinator-attracting petal spots of the beetle daisy, Gorteria diffusa (Asteraceae). American Journal of Botany, 96, 2184-2196.

Turner, G. W., Gershenzon, J., \& Croteau, R. B. (2000). Development of peltate glandular trichomes of peppermint. Plant Physiology, 124, 665-679.

Uzelać, B., Janošević, D., Stojičić, D., \& Budimir, S. (2017). Morphogenesis and developmental ultrastructure of Nicotiana tabacum short glandular trichomes. Microscopy Research and Technique, 80(7), 779-786.

van Rensburg, C., Erasmus, E., Loots, D., Oosthuizen, W., Jerling, J., Kruger, H., ... van der Westhuizen, F. (2005). Rosa roxburghii supplementation in a controlled feeding study increases plasma antioxidant capacity and glutathione redox state. European Journal of Nutrition, 44, 452-457.

Venditti, A., Bianco, A., Nicoletti, M., Quassinti, L., Bramucci, M., Lupidi, G., \& Maggi, F. (2014). Characterization of secondary metabolites,biological activity and glandular trichomes of Stachys tymphaea Hausskn. From the Monty Sibillini National Park (Central Apennines, Italy). Chemistry and Biodiversity, 11, 245-261.

Wagner, G. J., Wang, E., \& Shepherd, R. W. (2004). New approaches for studying and exploiting an old protuberance, the plant trichome. Annals of Botany, 93, 3-11.

Wagner, G. J. (1991). Secreting glandular trichomes: More than just hairs. Plant Physiology, 96, 675-679.

Wang, D. J., Zeng, J. W., Ma, W. T., Lu, M., \& An, H. M. (2019). Morphological and structural characters of trichomes on various organs of Rosa roxburghii. HortScience, 54(1), 45-51.

Wang, Y. L., Nie, J. T., Chen, H. M., Guo, C. L., Pan, J., He, H. L., ... Cai, R. (2016). Identification and mapping of tril, a homeodomain-leucine zipper gene involved in multicellular trichome initiation in Cucumis sativus. Theoretical \& Applied Genetics, 129, 305.

Werker, E., \& Fahn, A. (1981). Secretory hairs of Inula viscosa (L.) Ait. Development, ultrastructure and secretion. Botanical Gazette, 142, 461-476.

Werker, E. (2000). Trichome diversity and development. Advances in Botanical Research, 31, 1-35.

Zhao, J., Pan, J., Guan, Y., Zhang, W., Bie, B., Wang, Y., ... Cai, L. (2015). Microtrichome as a class I homeodomain-leucine zipper gene regulates multicellular trichome development in Cucumis sativus. Journal of Integrative Plant Biology, 57, 925-935.

How to cite this article: Wang D-J, Lu M, Ludlow RA, Zeng J-W, Ma W-T, An H-M. Comparative ultrastructure of trichomes on various organs of Rosa roxburghii. Microsc Res Tech. 2021;84:2095-2103. https://doi.org/10.1002/jemt. $\underline{23765}$ 